\title{
Just Sick of It? : Health and Political Trust in Western Europe
}

\section{Mattila, Vesa Mikko}

2018-02

Mattila , V M \& Rapeli , L 2018 , ' Just Sick of It? Health and Political Trust in Western

Europe ' , European Journal of Political Research , vol. 57 , no. 1 , pp. 116-134 . https://doi.org/10.1111/1475-6765.1

http://hdl.handle.net/10138/321493

https://doi.org/10.1111/1475-6765.12218

unspecified

acceptedVersion

Downloaded from Helda, University of Helsinki institutional repository.

This is an electronic reprint of the original article.

This reprint may differ from the original in pagination and typographic detail.

Please cite the original version. 


\title{
JUST SICK OF IT? HEALTH AND POLITICAL TRUST IN WESTERN EUROPE
}

\author{
Mikko Mattila \\ Department of Political and Economic Studies, University of Helsinki \\ Lauri Rapeli \\ Social Science Research Institute, Åbo Akademi University
}

Accepted for publication in European Journal of Political Research

\begin{abstract}
We explore two theoretical possibilities for why personal health may affect political trust: the psychological-democratic contract theory and the role of personal experience in opinion formation. We argue that citizens with health impairments are more likely to experience the direct effects of political decisions, as they are more dependent on public health services. Negative subjective evaluations of public services can lower trust levels, especially if people's expectations are high. Using European Social Survey data, we analyse the association between health and trust in 19 Western European states. The results indicate that people in poor health exhibit lower levels of trust towards the political system than people in good health. The differences in trust between those in good and poor health are accentuated among citizens with left-leaning ideological values. Our results suggest that welfare issues may constitute a rare context in which personal, rather than collective, experiences affect opinion formation.
\end{abstract}

Keywords: Health; Political trust; Welfare state; Public health services; Opinion formation 
Introduction

In recent years, interest in the association between personal health and political engagement has grown in popularity among political scientists. Although causal mechanisms understandably still remain elusive, the point of departure in the literature is that poor health leads to diminished political activity. Findings show that poor health depresses turnout (e.g., Mattila et al. 2013; Pacheco \& Fletcher 2015) but not necessarily the likelihood of participating through other forms of political action (Söderlund \& Rapeli 2015). This latter observation could be explained by differing levels of political trust among those with and without health problems, because previous studies have shown that high levels of political trust are positively associated with institutional participation and negatively with non-institutional forms of participation (Hooghe \& Marien 2013). In this study, we analyse if and how personal health is connected to political trust and whether this relationship is dependent on modifying factors, such as individuals' political ideology or their welfare state context.

The relationship between personal health and political trust has not previously been analysed in a comparative setting using data from several countries, although there are two single countries studies on the topic from Sweden (Lindström \& Mohseni 2009; Mohseni \& Lindström 2007). In this study, we employ the European Social Survey data to analyse the trust-health linkage in 19 West European countries. We assume that citizens with health impairments are more likely to experience the direct effects of political decisions, as they are more dependent on the welfare and health services provided by the public sector. This first-hand experience may lower their levels of trust towards the political system and its actors, especially in cases where they judge the quality of public services to be insufficient.

To make the theoretical connection between personal health and political trust, we suggest two potential pathways. Our starting point is the idea of an implicit psychological-democratic contract, which affects individuals' levels of political trust (Wroe 2014). The contract theory assumes that citizens have normative expectations of how the political system should perform and that deviations from these expectations are seen as breaches of the contract, which, in turn, will lead to an erosion of political trust. Then, we examine the relationship between health and political trust with two hypotheses representing breaches of the contract. The first one explores the modifying effect of ideology on the health-trust relationship. We expect the effect of health on trust to be stronger among those positioning themselves in the political left. The second one approaches health and trust 
from the perspective of attitude formation. While previous literature has typically found sociotropic perceptions to be crucial for the development of political attitudes and opinions, health and trust is a potential exception, in which it is personal perceptions, rather than elite cues or collective experiences that affect attitude formation (Kumlin 2002). With this twofold theoretical approach, the study contributes to two distinct research agendas: the expanding literature on the relationship between personal health and political behaviour, and the more traditional literature on public opinion formation.

Our empirical results from the European Social Survey data indicate that people in poor health usually exhibit lower levels of political trust than people in good health. The differences in trust between those in good and those in poor health become emphasized among citizens with leftleaning ideological values. The effect of poor health on trust is smallest in Southern regimes, which are characterized by relatively modest welfare systems. We also provide support for the original contention by Kumlin (2002) that, unlike in most other instances, personal evaluations affect the formation of a sense of political trust in the context of health issues.

Previous studies on trust and health

A number of influential studies have considered societal trust to be a determinant of societal wellbeing and economic prosperity (e.g., Fukuyama 1995; Putnam 2000). Others have, by contrast, viewed trust as a product of the performance of political institutions, rather than a root cause of it (e.g., Miller \& Listhaug 1990: 358). Rothstein \& Stolle (2008) call the former the 'society-centered' model and the latter the 'institution-centered' model of social capital, which is intrinsically linked to political trust. In terms of the institution-centred model, which emphasizes the role of government institutions in influencing popular levels of political trust, Rothstein \& Stolle distinguish between two types of trust: trust in representational political institutions (e.g., legislatures and politicians) and trust in the institutions that implement public policy (Rothstein \& Stolle 2008: 444-445). Others have, however, argued that citizens often in practice conflate different types of trust into a single, comprehensive, one-dimensional expression of political trust (Hooghe 2011). Accordingly, political trust is frequently measured with a single index, combining items indicating trust in both representational and policy institutions.

Previous studies have linked political trust to various factors, such as socio-demographic variables and political values (e.g., Listhaug \& Wiberg 1995), political regimes (e.g., Dimitrova-Grajzl 2010), 
institutional performance (e.g., Kestilä-Kekkonen \& Söderlund 2015; van Erkel \& van der Meer 2016), satisfaction with public services (e.g., Christensen \& Lægreid 2005) and even biological determinants (Merolla et al. 2013). Generally speaking, individual-level differences in political trust are particularly strongly related to cognitive ability and political awareness. In their extensive comparative study, Catterberg \& Moreno (2005) found a positive link between trust and political interest, efficacy and social capital. Additionally, economic wellbeing had a similar effect. Using data from Finland, Bäck \& Kestilä (2009) also found education and political interest to be important predictors of trust, although they also found that age was negatively related to trust. Young people therefore seem more distrusting of the political establishment. Politically trusting individuals are, intuitively, much more likely to engage in politics through voting, suggesting that political trust is typically related to conventional patterns of political behaviour (Grönlund \& Setälä, 2007).

The type of political trust that is specifically related to the performance of the political system is what David Easton (1965) originally referred to as 'support for the output of government'. Only a few studies have looked at trust in output in terms of public healthcare. Van de Walle et al. (2005) have shown that people with low levels of institutional trust may nevertheless be quite trusting of specific public services (also Christensen \& Lægreid 2005: 488). In similar fashion, experiences of dealing with public authorities often lead to positive assessments, even if diffuse support for the system as a whole is low (e.g., Goodsell 1994). In a comprehensive study of welfare attitudes in Sweden, Kumlin (2002) found that personal involvement in public services determines to a great extent a person's attitude: experience of injustice in the implementation of public policy reduces political trust. This is related to the general design of welfare state institutions. Contact with universal welfare state institutions increases trust, while experience with social programmes that use needs-testing undermines it (Kumlin \& Rothstein 2005).

Using Swedish survey data, two studies have looked at personal health in conjunction with political trust. Lindström (2011) argues that health is affected by personal political attitudes, such as political trust, because they relate to the extent to which 'a person believes that there is a possibility to influence one's health by modifying behavior' (Lindström 2011: 3). As Lindström demonstrates, the sense that one's influence over personal health is weak can be related to low levels of trust in the (Swedish) parliament. Lindström \& Mohseni (2009) reached a similar conclusion regarding self-rated mental health, which was also linked to poor institutional trust. In a third study from Sweden, Mohseni \& Lindström (2007) found that low trust in the healthcare system is associated with poor self-rated health. Although the cross-sectional data could not reveal any causal 
mechanism, the authors speculate that access to health services is likely to affect this relationship: low levels of political trust may cause people to seek medical help too late, thus affecting the effectiveness of the treatment. This may then further contribute to low levels of trust in the healthcare system, when the resulting personal evaluations are negative.

Summarising the literature on health and political trust is a risky venture because it consists of two studies from a single country with no uniform theoretical foundation underlying the analyses. The existing research nevertheless shows that poor personal health and low political trust are linked, although the theoretical understanding behind this finding is largely lacking. The evidence does, however, suggest that citizens' personal experiences with public authorities affect public trust in the output side of politics. This supports the idea that political institutions generate - or depress political trust, as assumed by the institution-centred model.

Although we too are unable to assess causality due to the nature of the data, in contrast to the previous contributions by Lindström et al., we assume that causality runs from health toward trust. In other words, whereas the few previous studies have suggested that political attitudes such as trust lead to variations in personal health, we suggest that variations in personal health lead to differences in trust (although keeping in mind the possibility of reverse causality). To address the apparent deficiency in the theoretical understanding of precisely why health and trust could be linked, we propose two possible theoretical approaches that could help us understand the complex relationship between political trust and health.

Theoretical approaches and hypotheses

One way to approach political trust is to understand it as a psychological relationship between citizens and the institutions of a political system. Individuals' levels of trust depend on 'evaluations of whether or not political authorities and institutions are performing in accordance with the normative expectations held by the public' (Miller \& Listhaug 1990: 358). In very similar vein, Wroe (2014) has recently conceptualized the trust relationship as an implicit 'psychologicaldemocratic trust contract' based on perceived mutual obligations: individuals extend their trust and loyalty to a political system and its actors only when they feel that they are receiving enough material or immaterial benefits from the system. At its most basic, trust is predicated both on the actual performance of a political system and on normative citizen expectations of how the system should perform. Citizens expect a certain level of benefits from the system (such as security or a 
reasonable level of material wellbeing) and if the system cannot deliver, this is seen as a breach of the contract. Thus, it is not just the quality and quantity of government output as such that determines trust; it is also the gap between expectations and reality. Wroe has applied this idea to job insecurity. He assumed that individual-level 'job insecurity violates the psychologicaldemocratic contract, and workers respond by reducing their political trust' (Wroe 2014: 94). His empirical results showed that job insecurity indeed generates lower levels of trust in politicians, political parties and political institutions, and lower levels of satisfaction with democratic performance.

It seems reasonable to assume that health and political trust are related. Although we are restricted by our reliance on survey data, we follow previous literature in implicitly assuming that if there is a causal direction to be discovered, it points from poor health to political trust. But what mechanisms could explain why trust levels are lower among those with health problems?

In the following, we suggest that there is a direct relationship between health and political trust and, furthermore, that this relationship is modified by contextual factors. There are several reasons for expecting health and trust to be directly linked. Health problems, like other adverse life circumstances, may exhaust a person's physiological and mental resources, leaving less capacity for political engagement. Health impairments are often accompanied by increased levels of stress and depression which may lead to feelings of frustration, and which, in turn, may be reflected in a negative evaluation of the surrounding world, including the political institutions (Ojeda 2015). Like all forms of inequalities, health inequalities undermine prosocial attitudes because they increase the social distance between individuals, which, again, leads to an erosion of trust (Gallego 2016). Finally, as Uslaner (2002) has theorised, being in a disadvantageous social position, in this case due to poor health, is linked to pessimism about the future, which can also manifest itself as low political trust.

Furthermore, the psychological-democratic contract theory provides a mechanism linking health to political trust through the possible imbalance between the expectations and the reality of government outputs. It is likely that most people who fall ill do not, at least explicitly, blame the government or the political system for their health problems. They are more likely, however, to blame the political system if they feel that it would not support and care for them if and when they experience health problems. Thus, if the public sector cannot provide enough high-quality health 
services or related financial support, those in poor health may see this as a breach of the contract and reduce their levels of political trust in response.

From the viewpoint of psychological-democratic contract theory, then, the effect of health on political trust is modified by an individual's expectations regarding the general role of the public sector. These expectations are, in turn, related to individuals' ideological orientations, especially to self-placement on the left-right dimension. Although the exact meaning of ideological left and right is difficult, if not impossible, to define (see Mair 2007), one can safely assume that those identifying themselves with the left are more likely to emphasize an extensive public sector responsibility for citizen wellbeing than those on the right (Kumlin 2007b). Leftist ideology stresses collective responsibility, meaning that those identifying with the left are more likely to have higher expectations of what the state should do in terms of providing healthcare services. Those on the right are more likely to see health problems as individual problems and put less weight on the role of public healthcare. Making essentially the same argument, Anderson and Singer (2008: 574) write that 'people's ideological predispositions should motivate them to connect inequality with their views of the political system in different ways. Specifically, ideology is expected to act as a screen for how people view inequality and the extent to which they use it to judge the performance of the political system. Those who locate themselves on the right are likely to view inequality less negatively than those who do not. As a result, the effects of inequality on attitudes toward government should be muted among those on the right and more substantial among those on the left.' (See also van der Meer \& Hakhverdian, 2017). The bigger the gap between the expectations and the reality of health services, as experienced by people with health impairments, the stronger the feeling of the psychological-democratic contract being breached. We therefore hypothesize:

H1: The association between health and political trust is stronger among those who identify themselves on the left.

In addition, we hypothesise that the relationship between health and political trust is modified by persons' evaluations of the condition of public health services in their country. Thus, one approach would be to consider the effect of health on political trust as a function of personal, rather than collective evaluations. It is widely held that attitude formation is typically affected more by collective, sociotropic influences than by personal experiences (e.g., Egan and Mullin 2012). The role of elites and the mass media in creating a sense of collective perception has been seen as more influential on people's attitudes than the role of important, personal life events. Although such 
events may be dramatic for the individual, the personal is often regarded as non-political. The impact of the collective on political behaviour is enhanced by the mass media, which simultaneously downplays the importance of the personal (Mutz 1992). This has proven particularly true within the study of economic voting, where findings from various national contexts tend to confirm that voters rely on national-level economic indicators to pass judgement on office-holders, with little consideration for personal economic conditions (see, e.g., Lewis-Beck \& Paldam 2000; Lewis-Beck \& Whitten 2013; but also Hansford \& Gomez 2015).

Yet as Kumlin (2002: 14-15) has argued, the welfare state could constitute an environment in which the personal overrides the collective, because people have such intimate contacts with its institutions - particularly in terms of healthcare. In a recent study Margalit (2013) shows that personal difficulties, especially becoming unemployed, significantly increased favouring welfare policies. Margalit found welfare support to grow more among Republicans who experienced hardship, even accounting for the fact that Democrats were more supportive to begin with. This suggests that personal considerations really might be more salient in health-related opinion formation. Henderson \& Hillygus (2011) provide another example by showing that healthcare attitudes in the US are often affected by self-interest considerations instead of party identification or ideological conviction.

It therefore seems that whereas politics and politicians may otherwise seem impersonal and distant, health problems, and welfare issues more generally, connect the individual with the outputs of a political system in a very direct manner. Citizens in modern (welfare) states have more direct contact with public service providers than before, and it is through this contact that they fundamentally form attitudes towards the political system. Consequently, dissatisfaction with public services in general is likely to lower political trust, and for those who are experiencing health problems, the availability and quality of health services is probably particularly salient. Thus, we assume that people with health problems who make a negative evaluation of the state of the health services in their country display less political trust (H2) (see also Kumlin 2007a).

$\mathrm{H} 2$ : The association between health and political trust is stronger among those with a negative evaluations of health services

We therefore argue that among people with health problems, the importance of public health services increases relative to other fields of public policy, i.e., the evaluation of health services 
carries more weight in their 'trust function'. Accordingly, we assume that poor health is related to trust more closely among people with high levels of dissatisfaction. In technical terms, this means we expect a negative interaction between poor health and negative evaluations of healthcare services, so that these two factors jointly reinforce the negative impact on trust.

Similar arguments for the psychological-democratic trust contract can be made on the contextual level as well. Different welfare regimes emphasize the role of the state differently. Since EspingAndersen's classic book (1990), the welfare regime literature has burgeoned and the original typology has been expanded from three regimes to include the Southern and Eastern European regimes. Different welfare state regimes emphasize the idea of universalism differently.

Universalism entails public services that are granted to everyone without means testing on the basis of social citizenship, and a state that is strongly interventionist in its efforts to produce social equality (Eikemo \& Bambra 2008). The principles of universalism and egalitarianism are most pronounced in the states belonging to the social democratic (or Scandinavian) welfare regime. With regard to the psychological-democratic contract, universalist welfare states have made a strong commitment to ensure the wellbeing of their citizens, which may, in turn, raise citizens' expectations to a higher level than those in states with less extensive welfare systems. Thus, people with health problems living in welfare regimes with comprehensive universal public services are more likely to exhibit lower levels of trust - as compared to those in good health - than people living in countries where the state has not made such a strong commitment to universalism and the extensive provision of services.

H3: The relationship between poor health and political trust is strongest in welfare regimes with comprehensive universal public services.

We test these hypotheses in 19 European states, using the European Social Survey data, which we will introduce in the next section.

Data and variables

In the empirical analysis, we use the six rounds of the European Social Survey data from 20022012. Each ESS round is based on a random sample of persons aged 15 and over, with national sample sizes of approximately 1,500 people (or 800 in countries with populations of less than a 
million). In our analysis we only include respondents who were eligible to vote at the time of the survey.

We have excluded the post-communist Eastern European countries from the analysis for a variety of reasons. Firstly, the number of non-responses in the variable measuring respondent's left-right placement is very high in many Eastern European countries. Including Eastern Europe in the analysis leads to approximately 30,000 missing cases in analyses employing left-right selfplacement. Secondly, given the political past of the post-communist countries, the meanings attached to the concept of left-right politics are partly different when compared with Western European democracies (Pop-Eleches \& Tucker 2010). Thirdly, the relationship between social status and political trust also shows a different pattern in Eastern European countries compared with Western European countries. As Hakhverdian \& Mayne (2012) have shown, in the West education and trust have a positive relationship, but in post-communist societies the same relationship is negative. Fourthly and perhaps most importantly, evidence suggests that while self-rated health is a reasonably sound cross-national measure of personal health among the various Western European countries, response styles in Eastern Europe are different to the extent that comparisons become unstable (Carlson 1998). Restricting the analysis to Western European nations effectively avoids the pitfalls of cross-national inconsistencies in self-rated health measurement.

On these grounds it seems likely that including Eastern European countries would cause unwanted unreliability in our attempt to understand the possible linkages between health and political trust. Although it is an unfortunate trade-off, we consider concentrating only on Western European countries the lesser of two evils, since we are primarily interested in a sound analysis of health visá-vis political trust, not in disentangling the differences between Eastern and Western European countries.

The dependent variable in the analysis is political trust. We have operationalized political trust using an additive index formed by five items, measuring trust in the five most important institutions of a political system (Hooghe \& Marien 2013). These institutions are the parliament, the legal system, the police, politicians and political parties. The actual wording of the trust items was as follows: "please tell me on a score of 0-10 how much you personally trust each of the institutions I read out. 0 means you do not trust an institution at all, and 10 means you have complete trust.' To calculate the index, all five items were summed together and then divided by five to preserve the original 0-10 scale. All the items load strongly on a single dimension and Cronbach's $\alpha$ for the trust 
index is high (0.89). Of the five institutions, the legal system and, particularly, the police are not directly involved in the provision of health care services. However, we included these items to our measure of political trust as we want our dependent variable to measure a broad conception of trust, not just concentrating only on those institutions who are involved in making the political decisions. As the trust items are strongly correlated with each other, this decision has little bearing on the empirical results.

Individuals' health was measured with the standard self-rated health question typically used in population-level health studies. As one of the most widely used single-item indicators of health in sociological medicine since the 1950s (Jylhä 2009: 307), self-rated health can reliably predict various aspects of health and health-promoting behaviour (e.g., Fylkesnes \& Forde 1992)1. The question wording was: 'How is your health in general?' Respondents were given five response categories coded from 1 to 5: 'Very good' (26\% of respondents), 'Good' (44\%), 'Fair' (23\%), 'Bad' $(6 \%)$ and 'Very bad' $(1 \%)$. For the analysis, we reversed the coding so that high values indicate better subjective health and employed it as a continuous variable (see Pacheco \& Fletcher 2015). We also repeated the analyses with dummies, using the health variable as a categorical variable, and the results were practically identical.

Respondents' assessment of the general state of the healthcare system in their home country was asked with the following question: 'Please say what you think overall about the state of health services in [country] nowadays?' The respondents were able to express their assessment on a scale ranging from 0 ('Extremely bad') to 10 ('Extremely good'). Ideally, we would have used a direct evaluation of personal experiences with public healthcare services but, unfortunately, such an item was not available in the dataset. Respondents' ideological self-placement on the left-right scale was similarly asked on an 11-point scale, with higher scores indicating a more 'rightist' placement. We use this variable to measure individuals' opinions on the preferred extent of the public sector responsibility as a proxy, because the dataset did not include a direct question on this matter. The third hypothesis requires that the countries represented by the data be grouped into categories according to welfare state type. This task is complicated by the fact that different authors use different classification systems, because the lines between categories are somewhat blurred. Only a few countries represent pure types of each welfare regime, while the rest fall somewhere between categories (Ferragina \& Seeleib-Kaiser 2011). Furthermore, there are numerous classifications aimed specifically at categorising health care systems (Reibling 2010; Böhm et al. 2013). However, we chose to use more general welfare regime categorisations as they reflect more closely the way 
political trust is related to citizen expectations. It is not only health care services that matter (although they are very relevant) but also the other support forms that the state offers. This includes all kinds of public benefits that support individuals and families in health troubles such as disability pensions, access to day care services for children, support for medical expenses etc.

Despite these difficulties, our analysis follows the fairly comprehensive classification system by Richter et al. (2012), as they use almost exactly the same countries as we do. The countries are grouped into four welfare regimes. For the purposes of this study, the social democratic welfare states are the most interesting group, as they represent countries with the most universalist welfare commitment. The other regimes are the conservative, liberal and Southern European regimes. ${ }^{2}$ Conservative welfare states typically emphasize earnings-related benefits, with minimal redistributive impact. In liberal welfare states, the benefits are typically small and recipients are usually means-tested. Southern European welfare states are characterized by a fragmented system of welfare provision; in these countries the healthcare systems provide only limited coverage (Eikemo \& Bambra 2007).

As demographic control variables we use age, age squared and gender. Controlling for age is important, as both health and political trust are affected by age. The models include respondents' level of education, which is also associated with political trust (e.g., van Elsas 2015). Furthermore, individuals' levels of trust are at least partly attributable to their general standing in the society. To control for this, we include respondents' main source of income as an independent variable. With this variable we can distinguish, for example, respondents who are outside labour markets (retired, unemployed) or who are self-employed.

We do not include such mediating variables as interest in politics, party identification or personal efficacy in the models, as they could distort the relationship between our main independent variable (health) and the variable measuring political trust. These mediating factors are likely to be located somewhere between health and political trust in the 'causal chain'. Controlling for them could introduce post-treatment bias in the analysis and alter the estimates of the total effect of health on trust. For example, including political interest in the models may reduce the coefficient for the health variable, but this would not mean that health has a smaller total effect on trust. This is because, in this model, health would have — in addition to a direct effect - an indirect effect on trust: poor health lowers interest in politics, which in turn lowers trust levels. 
However, the choice of appropriate controls is a difficult decision to make. Age and gender are measured before 'treatment' (health) and, consequently, should not muddy the interpretation of the association between health and trust. The case is more complicated for education and the variable indicating the main source of income. For example, health problems experienced in early life may prevent persons from getting a good education but the causality can run in the other way as well: high education is connected to better health behaviours which can prevent individuals from getting ill. A similar two-way relationship may exist between, e.g., unemployment and health. To be more confident of our empirical results, we present additional models in the web-appendix with alternative sets of control variables.

\section{Results}

We begin the analysis with a simple description of the association between the two main variables of interest in this study. Table 1 presents a cross tabulation of respondents' self-rated health and their level of political trust, both categorized into three groups. The figures show that there is an apparent bi-variate association between the variables. About a third (32\%) of the respondents with good or very good health have high levels of political trust, whereas only $18 \%$ of those with bad or very bad health condition belong to the same group. Of those with poor heath, $46 \%$ belong to the group with low trust levels, while the corresponding figure for those in good health is only $27 \%$.

Table 1. Self-rated health and political trust $\left(\% ; \mathrm{X}^{2}\right.$-test $\left.\mathrm{p}<0.01\right)$.

\begin{tabular}{|l|c|c|c|}
\hline & \multicolumn{3}{|c|}{ Self-Rated Health } \\
\hline Political trust & Very good/Good & Fair & Bad / Very Bad \\
\hline Low trust (<4) & 27 & 35 & 46 \\
\hline Medium trust (4-6) & 41 & 41 & 36 \\
\hline High trust (>6) & 32 & 24 & 18 \\
\hline & $100 \%$ & $100 \%$ & $100 \%$ \\
$\mathrm{~N}$ & 101,634 & 32,963 & 9,148 \\
\hline
\end{tabular}

The bivariate analysis does not take into account the nested multilevel nature of the data and possible confounding due to age or other factors. In the multivariate analysis, we model the data as a three-level structure where individuals are on the first level, the second level is constituted by the country-ESS round combinations, and the third level by the countries themselves. This is a common way to analyse ESS data with several data waves in multiple countries (see, e.g., Persson 2013; Pichler 2010; van der Meer 2010) ${ }^{3}$. The models are random intercept models where the intercepts are allowed to vary on the second and third levels. In Table 2, we have grand-mean centred all continuous variables to ease the interpretation of the coefficients. As the analyses presented in 
Table 3 include cross-level interactions, we have used here group-mean centring (using countries as groups) (see Aguinis et al. 2013).

In Table 2, we test hypotheses $\mathrm{H} 1$ and $\mathrm{H} 2$ with linear multilevel regression models. The first model includes only self-rated health, along with the control variables. In order to test $\mathrm{H} 1$ and $\mathrm{H} 2$, the second model includes the assessment of the state of the health services and L-R position, and the third model includes the 'assessment + health' interaction effect. Model 1 confirms the underlying assumption that good health is positively associated with higher trust in a statistically significant way. The coefficient shows that the difference in trust between those in very good health and those in very bad health is about 1 point on the $0-10$ trust scale, meaning that the effect is relatively small in size. The results from Model 2 show that the effect of the assessment of the state of the healthcare services (measured on a $0-10$ scale) is also substantially larger in size than the effect of health.

Table 2. Effect of health, the assessment of health services and position on the Left-Right scale on political trust (multilevel regression, standard errors in parentheses, $* * \mathrm{p}<0.01, * \mathrm{p}<0.05$ )

\begin{tabular}{|c|c|c|c|c|c|}
\hline & Model 1 & Model 2 & Model 3 & Model 4 & Model 5 \\
\hline \multirow[t]{2}{*}{ Self-rated health } & $0.230 * *$ & $0.155^{* *}$ & $0.151 * *$ & $0.155^{* *}$ & $0.150 * *$ \\
\hline & $(0.006)$ & $(0.006)$ & $(0.006)$ & $(0.006)$ & $(0.006)$ \\
\hline \multirow[t]{2}{*}{ Assessment of health services } & - & $0.279 * *$ & $0.279 * *$ & $0.279 * *$ & $0.279 * *$ \\
\hline & & $(0.002)$ & $(0.002)$ & $(0.002)$ & $(0.002)$ \\
\hline \multirow[t]{2}{*}{ Left-right position } & - & $0.041 * *$ & $0.041 * *$ & $0.041 * *$ & $0.041 * *$ \\
\hline & & $(0.002)$ & $(0.002)$ & $(0.002)$ & $(0.002)$ \\
\hline \multirow[t]{2}{*}{ Assessment $\mathrm{x}$ health } & - & - & $0.011 * *$ & - & $0.011 * *$ \\
\hline & & & $(0.002)$ & & $(0.002)$ \\
\hline \multirow[t]{2}{*}{ LR position $x$ health } & - & - & - & -0.004 & $-0.005^{*}$ \\
\hline & & & & $(0.002)$ & $(0.002)$ \\
\hline \multirow[t]{2}{*}{ Education } & $0.044 * *$ & $0.042 * *$ & $0.042 * *$ & $0.042 * *$ & $0.042 * *$ \\
\hline & $(0.001)$ & $(0.001)$ & $(0.001)$ & $(0.001)$ & $(0.001)$ \\
\hline \multirow[t]{2}{*}{ Age } & $0.009 * *$ & $0.006 * *$ & $0.006 * *$ & $0.006 * *$ & $0.006 * *$ \\
\hline & $(0.001)$ & $(0.001)$ & $(0.001)$ & $(0.000)$ & $(0.000)$ \\
\hline \multirow[t]{2}{*}{$\mathrm{Age}^{2}$} & $0.000 * *$ & $0.000 * *$ & $0.000 * *$ & $0.000 * *$ & $0.000 * *$ \\
\hline & $(0.000)$ & $(0.000)$ & $(0.000)$ & $(0.000)$ & $(0.000)$ \\
\hline \multirow[t]{2}{*}{ Gender ( 1 = female $)$} & $-0.025 * *$ & $0.076 * *$ & $0.075 * *$ & $0.075 * *$ & $0.075 * *$ \\
\hline & $(0.008)$ & $(0.009)$ & $(0.009)$ & $(0.009)$ & $(0.009)$ \\
\hline \multicolumn{6}{|l|}{ Main source of income: } \\
\hline \multirow[t]{2}{*}{ Self-employment or farming } & $-0.085 * *$ & $-0.111 * *$ & $-0.111 * *$ & $-0.111 * *$ & $-0.111 * *$ \\
\hline & $(0.18)$ & $(0.018)$ & $(0.018)$ & $(0.018)$ & $(0.018)$ \\
\hline \multirow[t]{2}{*}{ Pension } & $-0.097 * *$ & $-0.101 * *$ & $-0.102 * *$ & $-0.101 * *$ & $-0.102 * *$ \\
\hline & $(0.017)$ & $(0.016)$ & $(0.016)$ & $(0.016)$ & $(0.016)$ \\
\hline \multirow[t]{2}{*}{ Unemployment benefit } & $-0.530 * *$ & $-0.470 * *$ & $-0.471 * *$ & $-0.469 * *$ & $-0.470 * *$ \\
\hline & $(0.029)$ & $(0.029)$ & $(0.029)$ & $(0.029)$ & $(0.029)$ \\
\hline
\end{tabular}




\begin{tabular}{lccccc} 
Other social benefit & $-0.259 * *$ & $-0.240 * *$ & $-0.242 * *$ & $-0.239 * *$ & $-0.241 * *$ \\
& $(0.027)$ & $(0.026)$ & $(0.026)$ & $(0.026)$ & $(0.026)$ \\
Other source & -0.009 & -0.032 & -0.032 & -0.032 & -0.032 \\
& $(0.033)$ & $(0.032)$ & $(0.032)$ & $(0.032)$ & $(0.032)$ \\
Constant & $4.861 * *$ & $4.652 * *$ & $4.650 * *$ & $4.653 * *$ & $4.651 * *$ \\
& $(0.181)$ & $(0.140)$ & $(0.140)$ & $(0.140)$ & $(0.140)$ \\
Random effects & & & & & \\
Country-level & 0.580 & 0.338 & 0.337 & 0.338 & 0.337 \\
& $(0.200)$ & $(0.118)$ & $(0.117)$ & $(0.118)$ & $(0.117)$ \\
ESS-round * country level & 0.131 & 0.099 & 0.099 & 0.099 & 0.099 \\
& $(0.024)$ & $(0.019)$ & $(0.018)$ & $(0.019)$ & $(0.018)$ \\
& & & & & \\
Observations & 134,583 & 122,164 & 122,164 & 122,164 & 122,164 \\
Log-likelihood & $-263,517$ & $-229,277$ & $-229,264$ & $-229,276$ & $-229,261$ \\
\hline
\end{tabular}

Dependent variable: political trust 1-10, higher values indicating more trust. Self-rated health: 1-5, higher values indicate better health. Assessment of the state of the health services: 1-10, high values indicate positive assessment. Left-right scale: $0-10$ with higher values indicating positions towards right. All the continuous variables are grand mean centred. The reference category in the main source of income variable is "Salary".

The statistical significance of an interaction term in the results does not necessarily mean that the interaction term is statistically significant over the whole range of the values of the conditioning variable. Thus, we used the methodology proposed by Berry et al. (2012) to confirm whether this is indeed the case. Figure 1 depicts the interaction results in a set of marginal effect plots. As interactions are always symmetrical, there are two plots for each of the two hypotheses. The plots show the marginal effect of the independent variables (y-axis) given the values of the conditioning variables (x-axis). The histograms in the background provide a general overview of the frequency distribution of the variable on the $\mathrm{x}$-axis. These analyses show that all the interaction terms reported in Tables 2 (Model 5) are significant over the whole ranges of conditioning factors. 
Figure 1. Marginal effect plots of the hypothesized interactions (dotted lines show $95 \%$ confidence intervals).
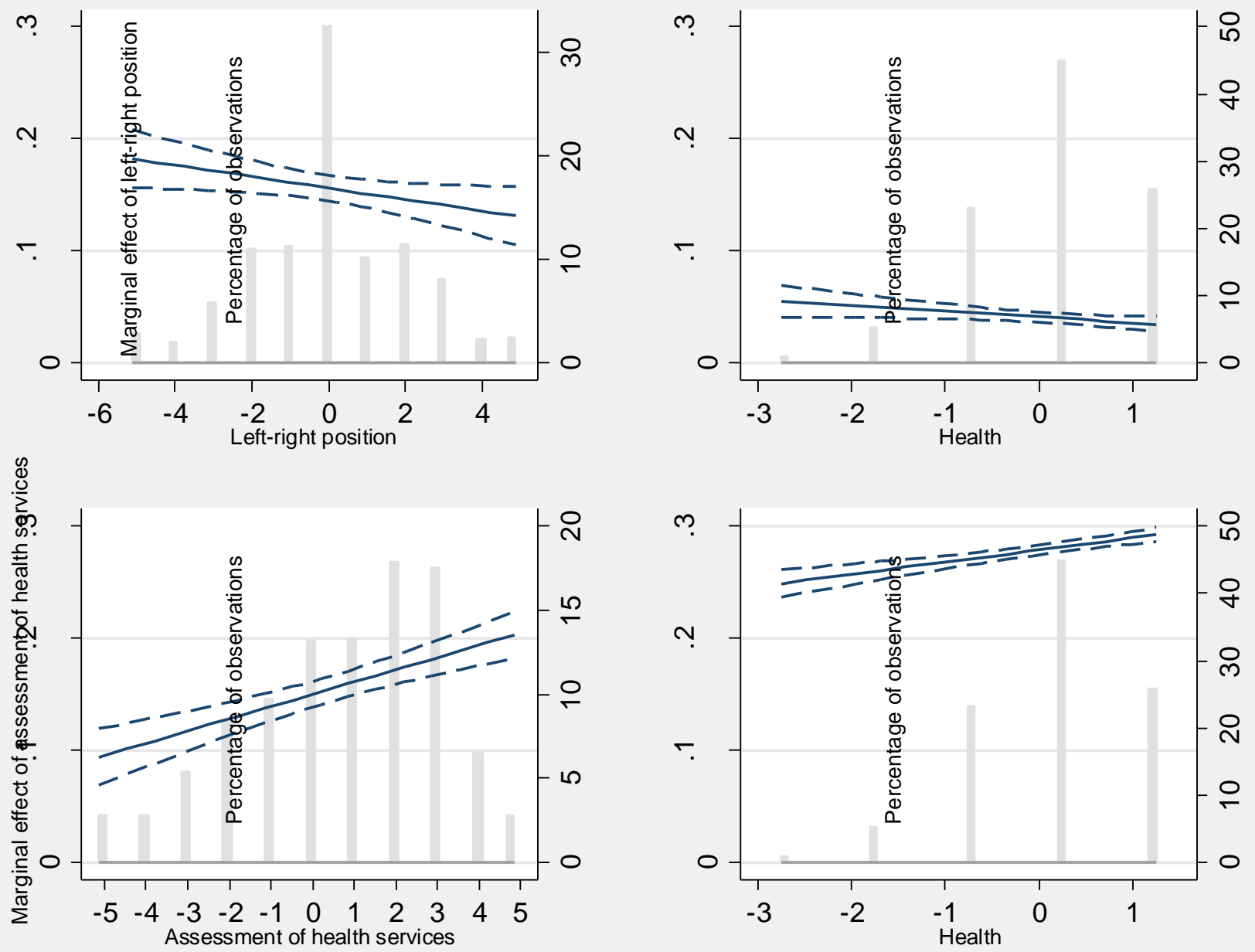

Note: The plots are based on results from Model 5 in Table 2 and are calculated with Stata 13 and Marhis program (Hernández 2016). The health, left-right position and assessment of health services variables are all group mean centred.

The interaction effect in Model 3 (as shown in Table 2) is statistically significant with a positive sign. This, in turn, contradicts $\mathrm{H} 2$, which assumed that a negative assessment of health services would affect trust more among those in poor health than among those with a better condition of health. In fact, however, it seems that this assessment carries more weight among people in good health, although the overall effect of the interaction term is quite modest. This finding is also confirmed in Model 5 in which all independent variables have been included simultaneously.

According to $\mathrm{H} 1$, the effect of health on political trust is dependent on a person's ideological position on the left-right dimension. The results in Table 2 show that political trust is indeed associated with ideology: people positioning themselves to the right are generally more trusting 
than those on the left. In Model 4, the interaction effect between health and ideology is not statistically significant. However, in the full model 5 it is and its sign is negative, providing support for the hypothesis that health conditions matter more among respondents on the left. However, the size of the coefficient on the interaction is again quite small. The finding that people report differing levels of political trust depending on who is holding office (Citrin \& Green 1986; Hetherington 1998) might call this observation into question. There is a risk that our result is produced by dissatisfaction with incumbents rather than (only) by self-placement in the political left. We consider this risk to be quite small, because of our multi-item measure of political trust and crossnational multi-wave survey data. Our trust indicator does not only measure trust in elected officials and is therefore less vulnerable for fluctuations in electoral success. Given the contextual and temporal breadth of the data (19 countries, six survey rounds in ten years), all types of electoral situations are well represented in our analysis, making a strong bias for any particular type of incumbency effect very unlikely.

In Table 3, we analyse how the effect of health on political trust varies between people living in different welfare regimes ${ }^{4}$. In general, political trust is highest in countries with a social democratic welfare system, followed by conservative welfare states and lowest in Southern European countries (Model 1). The interaction terms in Model 2 offer only partial support to the third hypothesis. The relationship between health and trust is affected by the type of the welfare state regime, but the interpretation of this relationship is not straightforward. The effect is smallest - i.e., trust differences between people in different health conditions are least pronounced — in the countries with Southern European welfare regimes (the marginal effect of health is practically zero in these countries: $0.228-0.283=-0.055)$. Trust differences between people with differing health statuses are largest in the Northern and Central European states with social democratic or conservative regimes. However, one should keep this observation in perspective; even people in very bad health in social democratic welfare states have higher predicted values of political trust (5.2; calculated with results in Model 5 in Table 2) than people in very good health in Southern (4.0) European welfare states. 
Table 3. Effect of health and welfare regime on political trust (multilevel regression, standard errors in parentheses, $* \mathrm{p}<0.05, * * \mathrm{p}<0.01)$.

\begin{tabular}{|c|c|c|}
\hline \multirow{2}{*}{ Self-rated health } & Model 1 & Model 2 \\
\hline & $\begin{array}{c}0.160 * * \\
(0.006)\end{array}$ & $\begin{array}{c}0.228 * * \\
(0.011)\end{array}$ \\
\hline Conservative regime & $\begin{array}{c}-0.854 * * \\
(0.259)\end{array}$ & $\begin{array}{c}-0.853^{* *} \\
(0.258)\end{array}$ \\
\hline Liberal regime & $\begin{array}{c}-1.347 * * \\
(0.362)\end{array}$ & $\begin{array}{c}-1.350 * * \\
(0.362)\end{array}$ \\
\hline Southern European regime & $\begin{array}{c}-1.905 * * \\
(0.279)\end{array}$ & $\begin{array}{c}-1.903 * * \\
(0.278)\end{array}$ \\
\hline Health x Conservative & - & $\begin{array}{l}-0.019 \\
(0.013)\end{array}$ \\
\hline Health x Liberal & - & $\begin{array}{c}-0.037^{*} \\
(0.017)\end{array}$ \\
\hline Health x Southern European & - & $\begin{array}{c}-0.238 * * \\
(0.015)\end{array}$ \\
\hline Assessment of health services & $\begin{array}{c}0.284 * * \\
(0.002)\end{array}$ & $\begin{array}{c}0.283^{* *} \\
(0.002)\end{array}$ \\
\hline Education & $\begin{array}{c}0.043^{* *} \\
(0.001)\end{array}$ & $\begin{array}{c}0.044^{* *} \\
(0.001)\end{array}$ \\
\hline Age & $\begin{array}{c}0.007 * * \\
(0.000)\end{array}$ & $\begin{array}{c}0.007 * * \\
(0.001)\end{array}$ \\
\hline $\mathrm{Age}^{2}$ & $\begin{array}{c}0.000 * * \\
(0.000)\end{array}$ & $\begin{array}{c}0.000 * * \\
(0.000)\end{array}$ \\
\hline Gender ( 1 = female $)$ & $\begin{array}{c}0.070^{* *} \\
(0.009)\end{array}$ & $\begin{array}{c}0.065^{* *} \\
(0.007)\end{array}$ \\
\hline \multicolumn{3}{|l|}{ Main source of income: } \\
\hline Self-employment or farming & $\begin{array}{c}-0.093 * * \\
(0.018)\end{array}$ & $\begin{array}{c}-0.090 * * \\
(0.017)\end{array}$ \\
\hline Pension & $\begin{array}{c}-0.103 * * \\
(0.016)\end{array}$ & $\begin{array}{c}-0.102 * * \\
(0.016)\end{array}$ \\
\hline Unemployment benefit & $\begin{array}{c}-0.504 * * \\
(0.028)\end{array}$ & $\begin{array}{c}-0.497 * * \\
(0.028)\end{array}$ \\
\hline Other social benefit & $\begin{array}{c}-0.268 * * \\
(0.025)\end{array}$ & $\begin{array}{c}-0.257 * * \\
(0.025)\end{array}$ \\
\hline Other source & $\begin{array}{l}-0.018 \\
(0.031)\end{array}$ & $\begin{array}{l}-0.016 \\
(0.031)\end{array}$ \\
\hline Constant & $\begin{array}{c}5.756 * * \\
(0.197)\end{array}$ & $\begin{array}{c}5.761 * * \\
(0.197)\end{array}$ \\
\hline \multicolumn{3}{|l|}{ Random effects } \\
\hline Country-level & $\begin{array}{c}0.166 \\
(0.063)\end{array}$ & $\begin{array}{c}0.165 \\
(0.063)\end{array}$ \\
\hline ESS-round $*$ country level & $\begin{array}{c}0.100 \\
(0.019)\end{array}$ & $\begin{array}{c}0.100 \\
(0.019)\end{array}$ \\
\hline Observations & 133,895 & 133,895 \\
\hline Log-likelihood & $-253,203$ & $-253,027$ \\
\hline
\end{tabular}




\section{Conclusions}

We have examined the link between health and political trust with the help of two explanatory models. Our point of departure was the psychological-democratic contract, which presumes that political trust is not only dependent on (dis)satisfaction with government output, but also on citizens' normative expectations of what the 'correct' level of these outputs should be. We applied this idea to study the relationship between health and political trust among citizens in 19 European countries. In general, our results were in line with the contract theory. They show that poor health is associated with reduced levels of political trust. The same is true for the direct effect of negative assessments of the state of the health services in one's home country and leftist ideology: they both lead to an erosion of trust.

We also argued that trust could be linked to health through personal perceptions rather than collective experience. If, as the contract theory suggests, political trust is influenced by the gap between citizens' expectations and their assessment of the reality of government outputs, the relationship between health and trust should be modified by the level of these expectations. High expectations may lead to disappointments when they are not met by people's actual experiences with public services. Our empirical findings partly support this line of reasoning, although not exactly as we hypothesized. Health's effect on trust is modified by person's assessment of the quality of health care services, but the effect is strongest among those with a positive opinion of the state of the services, Furthermore, the effect of health on political trust is partly dependent on individuals' ideological values. Those on the right are more trusting and among them health plays a smaller role in determining political trust; in contrast, among those leaning towards the left, health is a more important predictor of trust. Poor health combined with leftist ideology produces lowest levels of political trust.

Furthermore, political trust varies significantly between welfare state regimes. Trust in Western Europe is highest in social democratic welfare regimes, followed by conservative welfare regimes. It is lowest in the countries with Southern European welfare state regimes. However, inequality in political trust levels is also largest in Northern European welfare states: the smallest differences in trust levels between those in good and those in poor health can be found in the Southern European countries. Yet these relative differences should not mask the overall picture: people in very bad health in social democratic welfare states still have higher average levels of trust than people in very good health in countries where the general level of political trust is low. The national welfare state 
context, therefore, strongly affects the health-trust linkage at the individual level. To us it seems possible that this linkage can be at least partly explained by expectations: people do not expect as much from public health services in Southern European regimes as they do in other regimes. Consequently, while the overall levels of political trust are lower in Southern European regimes, poor performance by the public health sector does not affect these levels much, because it does not come as a disappointment to people (as it would in systems in which people's expectation are higher).

In general, our results contribute both to the literature on political trust and the literature on health and politics. First, the results show that normative expectations are an important predictor of trust and that the levels of these expectations vary between individuals in different life situations and between individuals with diverging ideological values. Second, researchers of the relationship between health and political participation have often struggled to elaborate the causal mechanisms linking health status with involvement in certain types of political activities. Studying how the differences in political trust among people with good and poor health affect their attitudes towards political participation should improve our understanding of these mechanisms substantially. Our results offer evidence of one such mechanism: the impact of personal expectations and experiences. As Kumlin (2002) has suggested, welfare issues seem to constitute a situation in which personal and not just collective - perceptions affect attitude formation. Furthermore, the welfare state in question, or the lack thereof, forms the backdrop against which people judge their own experiences. This pattern is most obvious in our finding that, although trust is generally highest in Scandinavian welfare states, individual-level differences are also particularly large in these countries. It seems that the dynamics of health and political trust vary depending on people's expectations concerning public healthcare. The Scandinavian model generates high expectations, and consequently also diversity in terms of individuals' disappointment or satisfaction with its output. While the evidence is not entirely conclusive, to us it strongly suggests that health problems are a factor that affects the formation of political trust also through evaluations of personal experience.

In this article, we presented results that are new both in the fields of research on political trust and on the health-political engagement relationship. However, our research design included some problems that must be taken into account when assessing our results and addressed in future studies. Certainly, the research design suffers from the problem of omitted variables. We have discussed some of these problems in the data section (e.g. omission of variables on the support for the incumbent parties, lack of a direct measure of personal experiences with public healthcare services). 
Furthermore, the reliability of our measure of health may be affected by cross-national differences in response style. Although by excluding Eastern European countries we have sought to minimize some of these problems regarding personal health and self-identification on the left-right dimension, there are still other unobserved respondent characteristics, which could affect our findings. As is obvious, people who are not well enough to answer a long survey as well as those who are extremely distrusting of politics fall outside of survey samples. Given the centrality of personal health and trust to our analysis, the systematic exclusion of such individuals undoubtedly affects our findings. Determining the size of the effect is beyond our reach, but we do not expect it to be substantial, because extremely poor health and a total lack of political trust are not very common characteristics on the population level. Consequently, we feel confident that our findings provide a realistic, if not entirely complete, picture of the relationship between health and political trust in Western Europe.

\section{Acknowledgements}

This research has been financially supported by the Academy of Finland (project 'Health and political engagement', grant number 1266844). We thank the anonymous reviewers for the valuable comments that helped us to improve the article.

\section{Notes}

${ }^{1}$ Although the group of countries included in the analysis is in many respects a very homogenous group, the evidence regarding cross-national validity of SRH is, however, mixed. See e.g. Idler \& Benyamini (1997), Carlson (1998), Sadana et al. (2002).

${ }^{2}$ Countries are grouped as follows: social democratic regimes (Denmark, Finland, Iceland, Norway, and Sweden); conservative regimes (Austria, Belgium, France, Germany, Luxembourg, the Netherlands, and Switzerland); liberal regimes (Ireland and the UK) and Southern European regimes (Cyprus, Greece, Italy, Portugal, and Spain).

3 There are still many open methodological issues with multilevel modelling of repeated multinational cross-sectional data (see e.g., Schmidt-Catran \& Fairbrother (2016) and Bryan \& Jenkins (2016)). This is why we performed a robustness check with a fixed effects specification. This did not change the results substantively (see Web appendix).

4 The UK is typically classified as a liberal welfare state. The UK health care system (NHS), however, share many features with the social democratic regimes. Thus, we tested also whether our results hold when the UK is not included in the group of liberal welfare states. This did not change the results markedly (see Web appendix).

\section{References}

Aguinis, H., Gottfredson, R.K. \& Culpepper S.A. (2013). Best-Practice Recommendations for Estimating Cross-Level Interaction Effects Using Multilevel Modeling. Journal of Management 39(6): 1490-1528. 
Anderson, C.J. \& Singer, M.M. (2008). The Sensitive Left and the Impervious Right: Multilevel Models and the Politics of Inequality, Ideology, and Legitimacy in Europe. Comparative Political Studies 41(4/5): 564-599.

Bryan, M.L. \& Jenkins, S.P. (2016). Multilevel Modelling of Country Effects: A Cautionary Tale. European Sociological Review 32(1): 3-22.

Bäck, M. \& Kestilä, E. (2009). Social Capital and Political Trust in Finland: An Individual-level Assessment. Scandinavian Political Studies 32(2): 171-194.

Berry, W.D., Golder, M. \& Milton, D. (2012). Improving Tests of Theories Positing Interaction. Journal of Politics 74(3): 653-671.

Böhm, K., Schmid, A., Götze, R., Landwehr, C. \& Rothgang, H. (2013). Five Types of OECD Healthcare Systems: Empirical results of a deductive classification. Health Policy 113(3): 258-269.

Carlson, P. (1998). Self-perceived health in east and west Europe: Another European health divide. Social Science and Medicine 46(1): 1355-1366.

Catterberg, G. \& Moreno, M. (2006). The Individual Bases of Political Trust: Trends in New and Established Democracies. International Journal of Public Opinion Research 18(1): 31-48.

Christensen, T. \& Lægreid, P. (2005). Trust in Governance: The Relative Importance of Service Satisfaction, Political Factors, and Demography. Public Performance \& Management Review 28(4): 487-511.

Citrin, J. \& Green, D. (1986). Presidential Leader- ship and the Resurgence of Trust in Government. British Journal of Political Science 16(4): 431-453.

Dimitrova-Grajzl, V. (2010). Political Trust and Historical Legacy: The Effect of Varieties of Socialism. East European Politics and Societies 24(2): 206-228.

Easton, D. (1965). A systems analysis of political life. New York: Wiley.

Egan, P. J. \& Mullin, M. (2012). Turning Personal Experience into Political Attitudes: The Effect of Local Weather on Americans' Perceptions about Global Warming. Journal of Politics 74(3): 796809.

Eikemo, T. \& Bambra, C. (2008). The welfare state: a glossary for public health. Journal of Epidemiology and Community Health 62(1): 3-6.

van Elsas, E. (2015). Political Trust as a Rational Attitude: A Comparison of the Nature of Political Trust across Different Levels of Education. Political Studies 63(5): 1158-1178.

van Erkel, P. \& van der Meer, T. (2016). Macroeconomic performance, political trust and the Great Recession: A multilevel analysis of the effects of within-country fluctuations in macroeconomic performance on political trust in 15 EU countries, 1999-2011. European Journal of Political Research 55(1): 177-197.

Esping-Andersen, G. (1990). The Three Worlds of Welfare Capitalism. Padstow: Polity Press. 
ESS (2012): European Social Survey Rounds 1-6 Data. Norwegian Social Science Data Services, Norway - Data Archive and distributor of ESS data.

Ferragina, E. \& Seeleib-Kaiser, M. (2011). Welfare regime debate: past, present, futures? Policy \& Politics 39(4): 583-611.

Fukuyama, F. (1995). Trust, the social virtues, and the creation of prosperity. New York: Free Press.

Fylkesnes, K. \& Forde, O. H. (1992). Determinants and dimensions involved in self-evaluation of health. Social Science \& Medicine 35(3): 271-279.

Gallego, A. (2016). Inequality and the erosion of trust among the poor: experimental evidence. Socio-Economic Review 14(3): 443-460.

Goodsell, C. (1994). The case for bureaucracy: A public administration polemic. Chatham: Chatham House.

Grönlund, K. \& Setälä, M. (2007). Political Trust, Satisfaction and Voter Turnout. Comparative European Politics 5(4): 400-422.

Hakhverdian, A. \& Mayne, Q. (2012). Institutional trust, education, and corruption: a micro-macro interactive approach. The Journal of Politics 74(3): 739-750.

Hansford, T. G. \& Gomez, B. (2015). Reevaluating the sociotropic economic voting hypothesis. Electoral Studies 39(1): 15-25.

Henderson, M. \& Hillygus, D. S. (2011). The Dynamics of Health Care Opinion, 2008 - 2010: Partisanship, Self-Interest, and Racial Resentment. Journal of Health Politics, Policy and Law 36(6): 945-960.

Hetherington, M. J. (1998). The Political Relevance of Political Trust. The American Political Science Review 92(4): 791-808.

Hooghe, M. (2011). Why There is Basically Only One Form of Political Trust. British Journal of Politics and International Relations 13(2): 269-275.

Hooghe, M. \& Marien, S. (2013). A Comparative Analysis of the Relation between Political Trust and Forms of Political Participation in Europe. European Societies 15(1): 131-152.

Idler, E.L. \& Benyamini, Y. (1997). Self-Rated Health and Mortality: A Review of Twenty-Seven Community Studies. Journal of Health and Social Behavior 38(1), 21-37.

Jylhä, M. (2009). What is self-rated health and why does it predict mortality? Towards a unified conceptual model. Social Science \& Medicine 69(3): 307-316.

Kestilä-Kekkonen, E \& Söderlund, P. (2015). Political Trust, Individual-level Characteristics and Institutional Performance: Evidence from Finland, 2004-13. Scandinavian Political Studies 39(2): 138-160. 
Kumlin, S. (2002). The Personal and the Political: How Personal Welfare State Experiences Affect Political Trust and Ideology. PhD thesis, Department of Political Science, Göteborg University.

Kumlin, S. (2007a). Overloaded or undermined? European Welfare States in the face of performance dissatisfaction. In S. Svallfors (ed.), The Political Sociology of the Welfare State. Stanford: Stanford University Press.

Kumlin, S. (2007b). The welfare state: Values, policy preferences, and performance evaluations. In R. Dalton and H-D. Klingemann (eds.), The Oxford Handbook of Political Behavior. Oxford: Oxford University Press.

Kumlin, S. \& Rothstein, B. (2005). Making and Breaking Social Capital: The Impact of Welfare State Institutions. Comparative Political Studies 38(4):339-365.

Lewis-Beck, M. S. \& Paldam, M. (2000). Economic voting: an introduction. Electoral Studies 19(2): 113-121.

Lewis-Beck, M. S. \& Whitten, G. (2013). Economics and elections: Effects deep and wide. Electoral Studies 32(3): 393-395.

Lindström, M. (2011). Social capital, political trust, and health locus of control: A population-based study. Scandinavian Journal of Public Health 39(1): 3-9.

Lindström, M. \& Mohseni, M. (2009). Social capital, political trust and self-reported psychological health: A population-based study. Social Science \& Medicine 68(3): 436-443.

Listhaug, O. \& Wiberg, M. (1995). Confidence in Political and Private Institutions. In H-D. Klingemann \& D. Fuchs (eds.), Citizens and the State. Oxford: Oxford University Press.

Mair, P. (2007). Left-right orientations. In R. Dalton \& H-D. Klingemann (eds.), The Oxford Handbook of Political Behavior. Oxford: Oxford University Press.

Margalit, Y. (2013). Explaining Social Policy Preferences: Evidence from the Great Recession. American Political Science Review 107(1): 80-103.

Mattila, M., Söderlund, P., Wass, H. \& Rapeli, L. (2013). Healthy voting: the effect of self-reported health on turnout in 30 countries. Electoral Studies 32(4): 886-891.

van der Meer, T. (2010). In what we trust? A multi-level study into trust in parliament as an evaluation of state characteristics. International Review of Administrative Sciences 76(3): 517-536.

van der Meer, T and A. Hakhverdian (2017). Political trust as the evaluation of process and performance: A cross-national study of forty-two European democracies. Political Studies 65(1): 81-102.

Merolla, J., Burnett, G., Pyle, K., Ahmadi, S., \& Zak, P. (2013). Oxytocin and the Biological Basis for Interpersonal and Political Trust. Political Behavior 35(4): 753-776. 
Miller, A. H. \& Listhaug, O. (1990). Political Parties and Confidence in Government: A Comparison of Norway, Sweden and the United States. British Journal of Political Science 20(3): 357-386.

Mohseni, M. \& Lindström, M. (2007). Social capital, trust in the health-care system and self-rated health: The role of access to health care in a population-based study. Social Science \& Medicine 64(7): 1373-1383.

Mutz, D. (1992). Mass Media and the Depoliticization of Personal Experience. American Journal of Political Science 36(2): 483-508.

Ojeda, C. (2015). Depression and Political Participation. Social Science Quarterly 95(5): 12261243.

Pacheco, J. \& Fletcher, J. (2015). Incorporating Health into Studies of Political Behavior: Evidence for Turnout and Partisanship. Political Research Quarterly 68(1): 104-116.

Persson, M. (2013). Is the Effect of Education on Voter Turnout Absolute or Relative? A Multilevel Analysis of 37 Countries. Journal of Elections, Public Opinion and Parties 23(2): 111-133.

Pichler, F. (2010). Foundations of anti-immigrant sentiment: The variable nature of perceived group threat across changing European societies, 2002-2006. International Journal of Comparative Sociology 51(6): 445-469.

Pop-Eleches, G. \& Tucker, J. A. (2010). 'After the Party: Legacies and Left-Right Distinctions in Post-Communist Countries. Juan March Foundation, Center for Advanced Study in the Social Science, Fundacion Juan March, Madrid, Spain, Working Paper Series, Estudio/Working Paper 2010/250.

Putnam, R. (2000). Bowling alone: The collapse and revival of American community. New York: Touchstone.

Reibling, N. (2010). Healthcare Systems in Europe: Towards an Incorporation of Patient Access. Journal of European Social Policy 20(1): 5-18.

Richter, M., Rathman, K., Gabhainn, S. N., Zambon, A., Boyce, W. \& Hurrelmann, K. (2012). Welfare state regimes, health and health inequalities in adolescence: a multilevel study in 32 countries. Sociology of Health \& Illness 34(6): 858-879.

Rothstein, B. \& Stolle, D. (2008). The State and Social Capital: An Institutional Theory of Generalized Trust. Comparative Politics 40(4): 441-459.

Sadana, R, Mathers, C. D., Lopez, A. D., Murray, C. J. L. \& Iburg, K. M. (2002). Comparative Analyses of More Than 50 Household Surveys on Health Status. In C. J. L. Murray, J. A. Solomon, C. D. Mathers, \& A. D. Lopez (eds.), Summary Measures of Population Health. 17 Concepts, Ethics, Measurements and Applications. Geneva: World Health Organization.

Schmidt-Catran, A.W. \& Fairbrother, M. (2016). The Random Effects in Multilevel Models: Getting Them Wrong and Getting Them Right. European Sociological Review 32(1): 23-38. 
Söderlund, P. \& Rapeli, L. (2015). In sickness and in health Personal health and political participation in the Nordic countries. Politics and the Life Sciences 34(1): 28-43.

Uslaner, E. M. (2002). The Moral Foundations of Trust. New York: Cambridge University Press.

van de Walle, S., Kampen, J. \& Bouckaert, G. (2005). Deep impact for high-impact agencies?

Public Performance \& Management Review 28(4): 532-549.

Wroe, A. (2014). Political trust and job insecurity in 18 European polities. Journal of Trust Research 4(2): 90-112. 